\title{
Structure of a Smart Grass Cutter Based on Solar Power
}

\author{
Shakti Prakash Jena, Saroj Kumar Acharya, Shashi Kant Behera
}

\begin{abstract}
According to the present technology commonly used manually operated devices or machines to cut the grass. In this project we introduce the smart grass cutting machine. The machine consisting of rotating blades operated by the DC motor, trolley to store the grass, hurdle removal and the system is operated by the electrical energy provided by the battery, and the solar panel is used to charge the battery. The main aim of the smart grass cutting device is to provide the operation of grass cutting at the desired area input by the user. This machine is designed to cut the grass at the desired height. Grass cutting employing a rotary blade which is rotated along the vertical axis are known as rotary mover. The requirement of electricity is increasing day by day at an alarming rate due to use of electrical gadgets and the growing amount of industries and the machines. Solar energy is a best alternative source of the energy.
\end{abstract}

Keywords- Solar panel, grass cutter, microcontroller, colour sensor, battery, solar charger, PMDC motor

\section{INTRODUCTION}

Nowadays, the major issue of the world is a pollution. The pollution is created by us and also pollution is being created day by day and can be seen anywhere around us[1]. The pollution can be any type either sound pollution, air pollution and many more. The grass cutter in practice is being run by fuel which emits gas, this can creates air pollution. Also the cost of the pollution is increasing day by day. Therefore, it is not efficient to use the grass cutter which is run by fuel. Hence solar power grass cutter has been introduced. Solar based grass cutter described as the grass cutter run by the conversion of solar energy into electrical energy which results in the rotation of blades of the grass cutter which does the moving of the lawn. As we know that solar energy is a renewable source of energy. In our project grass cutter we are aimed for the operation and construction of the machine. The panel should be placed on the suitable machine structure. Motor will be of high $10 \mathrm{k}$ RPM and the electric supply will be provided through the solar panel[2]. An electric switch is provided to control the operation on the machine. The frame will be prepared by using GI sheet and the other component are as motor, switch, wheel, wire, aluminium sheet, square pipe and insulating material and some standard materials. The manufacturing is done for the machine like grinding machine, welding machine etc. The grass cutter working principle is providing a high speed rotation to the blade. The

Revised Manuscript Received on September 10, 2019.

Shakti Prakash Jena, Mechanical Engineering, Siksha O Anusandhan Deemed to be University, Odisha, India.

(E-mail: shaktijena@soa.ac)

Saroj Kumar Acharya, Mechanical Engineering, Siksha O Anusandhan Deemed to be University, Odisha, India.

(E-mail: sarojacharya@soa.ac.in) Deemed to be University, Odisha, India.
Shashi Kant Behera, Mechanical Engineering, Siksha O Anusandhan

easier grass cutter to be used in the lawns, gardens and grass fields is electric cutter. To enhance the beauty of the grass fields, lawns and gardens the best available option is the proper cutting of the grass at proper time and it is done with the grass cutting machine. According to the report the maximum energy is being generated by the conventional fossil fuels and it is around $80 \%$ of the total energy generation, fuel like oils $36 \%$, natural gas $21 \%$ and coal $23 \%$. It is outstanding that the time isn't at present when all these source ought to be utilized to maintain a strategic distance from vitality showdown in the close-by future. So solar based vitality is acquaintance for machine process with work. A solar panel has rectangular and wide body, a grass cutter having solar hanger will be easy to operate. An electric grass cutter with the solar based hanger will be simpler to operate. It will brighten the emanation of an inward ignition mover which is for the most part in charge of which is for the most part duty for ecological contamination and causes green gases impact. To suit each and every particular need and convenience different design is prepared. The improvement in the electric grass cutter is a solar powered grass cutter.

\section{LITERATURE REVIEW}

The main yard cutter was developed by Edwin Budding in 1830 simply outside Surround, in Gloucestershire, England Bedding trimmer was structured principally to cut the grass on games grounds and broad greenhouses, as a better option than the sickle, and was allowed a British patent on August 31, 1830.Bedding's first machine was 1819 inches wide with an edge made up of formed iron. The grass trimmer was pushed from behind[3].

A Solar grass shaper is a machine that utilizations sliding cutting edges to cut a yard at an even length. Significantly increasingly complex gadgets are there in each field. Power utilization ends up basic for future. Solar powered grass shaper is a helpful gadget which is extremely straightforward in development. It is utilized to keep up and upkeep yards in greenhouses, schools, colleges and so on Quick development of different innovative apparatuses and gear's makes our employments done agreeable and refined. The exploration work goes for creating a grass cutting machine framework which makes the grass shaper based engine going through solar powered vitality. Strategic manoeuvres an incredible job wherever man lives and works. The cutting system is made of a level sharp edge unbendingly fixed to the casing behind the winding plan which is designed to contact at any rate one reel bar of the 
winding edges amid the revolution of the winding instrument[4].

\section{SYSTEM DETAILED DESCRIPTION}

\subsection{Motor}

A motor is a machine which convert the electrical energy into the mechanical energy. The magnetic field produces the forces of most expected common type. The DC motor is having some internal structure, either electronic or electromechanical, for the current flow change in the part of the motor body.

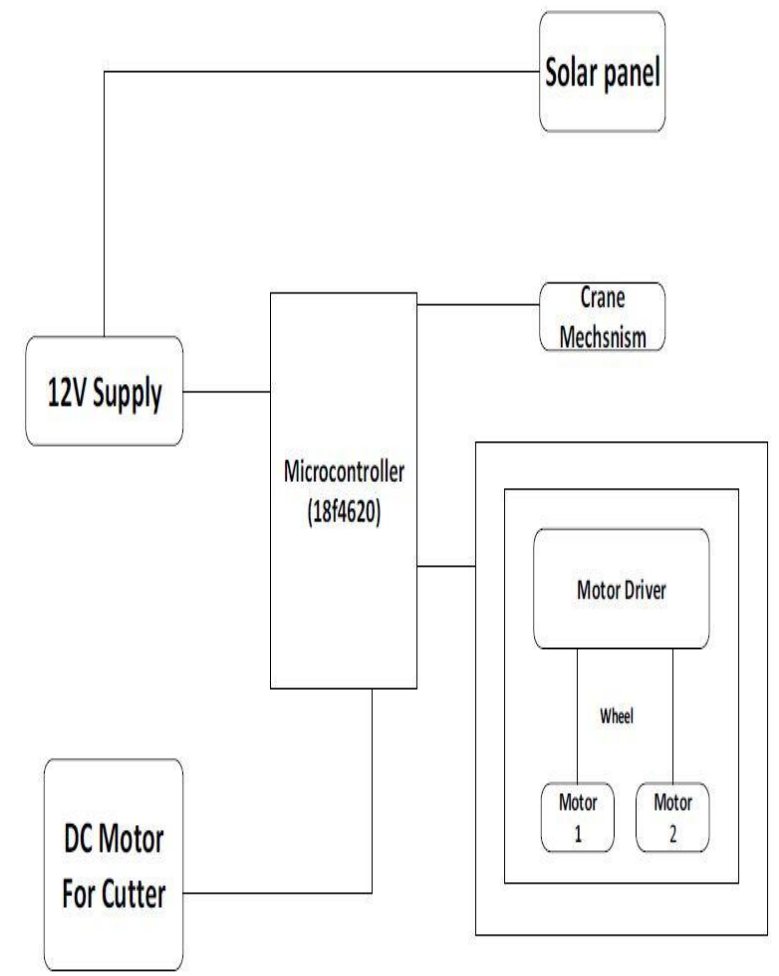

Figure 1. System block diagram

\subsection{Battery}

The battery consisting of the one or more electromechanical cells. Which provides power to the devices, machines, or the apparatus. There are many shapes and sizes of the battery. From miniature cell used in the battery to the large lead acid batteries used for the machines.

\subsection{Solar Panel}

Electrons are combined with holes which results the external conductor for the generation of the electrical energy. In this project the polycrystalline type solar panel is used. The photovoltaic principle is applied on the grass cutter. The production of the free electrons happens on the retention of the semiconductor devices on the falling of the photons on the solar panel. Solar energy is cheaper, ecofriendly and heavily available. Every module is appraised by its DC yield control under standard test conditions (STC), and normally extends from 100 to 320 watts. The ability of a module chooses the region of a module of particularly equivalent evaluated yields $8 \%$ capable 230 watt module will have double the region of a $16 \%$ productive 230 watt module. A solitary sun based module can create just a restricted measure of intensity; most establishments contain numerous modules[5].

\subsection{Microcontroller}

It is a single chip microcomputer created through VLSI fabrication. The microcontroller is embedded in the system for the controlling and monitoring of the components. It will receive and sends the information to the desired component for the functioning of the system. Preferably, Arduino Atmega328P is used in the system.

\subsection{Solar powered Charger}

The circuit is clear as crystal. A 12 volt 5 Watt solar based board is utilized as the wellspring of current. The cells in the board are comprised of semiconductor material which changes light vitality into electrical vitality. At the point when the daylight is most extreme, the solar oriented module can create around 16.5 volts at $400 \mathrm{~mA}$. This current is utilized to charge the battery.

\section{PROPOSED WORK \& RESULTS}

The smart grass cutter based on the solar power is used to fulfil all the objectives of the proposed idea we need to think and understand the basic elements of the electronic base are microcontroller, colour sensor, rechargeable battery, vacuum cleaner mechanism and DC motor.

\subsection{Arduino Atmega328P}

Arduino is cerebrum of generally framework. Arduino is single-board microcontroller proposed to make building intelligent items or situations increasingly open. Presented in 2005, the Arduino's originators tried to give a cheap and simple path for specialists, understudies, and experts to make gadgets that interface with their condition utilizing and actuators.

\subsection{Battery}

Rechargeable battery is used here in the system to reduce the running cost of the proposed system. The battery is selected as per the requirement of the components.

- $\quad \mathrm{VOLT}=12 \mathrm{~V}$

- $\quad$ CURRENT=7A

- $\quad \mathrm{WATT}=84 \mathrm{~W}$

\subsection{Solar Panel}

A solar panel consist of a photovoltaic modules set which is electrically connected to the system and paced on the top of the system. The solar panel are used herein for providing the electrical energy to the batteries.

- $\quad \mathrm{VOLT}=12 \mathrm{~V}$

- $\quad$ CURRENT=4.20A

- $\quad \mathrm{WATT}=84 \mathrm{~W}$

\subsection{Colour Sensor}

The sensor TCS230 shading light with utilizing of a variety of photodiodes an $8 * 8$ array.By utilizing a current to recurrence converter. The readings that the photodiode are changed over into a square wave with a recurrence straightforwardly relative to light force. The shading sensor played out the activity of detecting the grass and offer yield to microcontroller. 


\subsection{Vacuum cleaner}

The arrangement of the vacuum cleaner is like that the cutting grass suction and it stores the grass in the trolley at the required amount of pressure.

- $\quad \mathrm{VOLT}=12 \mathrm{~V}$

- $\quad$ CURRENT=8.33A

- WATT $=100 \mathrm{~W}$

\subsection{PMDC Motor for Wheel}

For the rotation of wheel two PMDC motors are embedded on the wheels.

- VOLT $=12 \mathrm{~V}$

- $\quad$ CURRENT=1.41A

- WATT $=17 \mathrm{~W}$

\subsection{PMDC Motor for Cutter}

For the rotation of the cutter at high speed the PMDC motor is used in this system.

- $\quad \mathrm{VOLT}=12 \mathrm{~V}$

- $\quad$ CURRENT=1A

- WATT $=12 \mathrm{~W}$

- $\quad$ SPEED=10000RPM

\subsection{PMDC Motor for Crane Mechanism}

For the removal of the small obstacles present on the path the PMDC motor is attached in the system.

- VOLT $=12 \mathrm{~V}$

- $\quad$ CURRENT=1A

- WATT $=12$

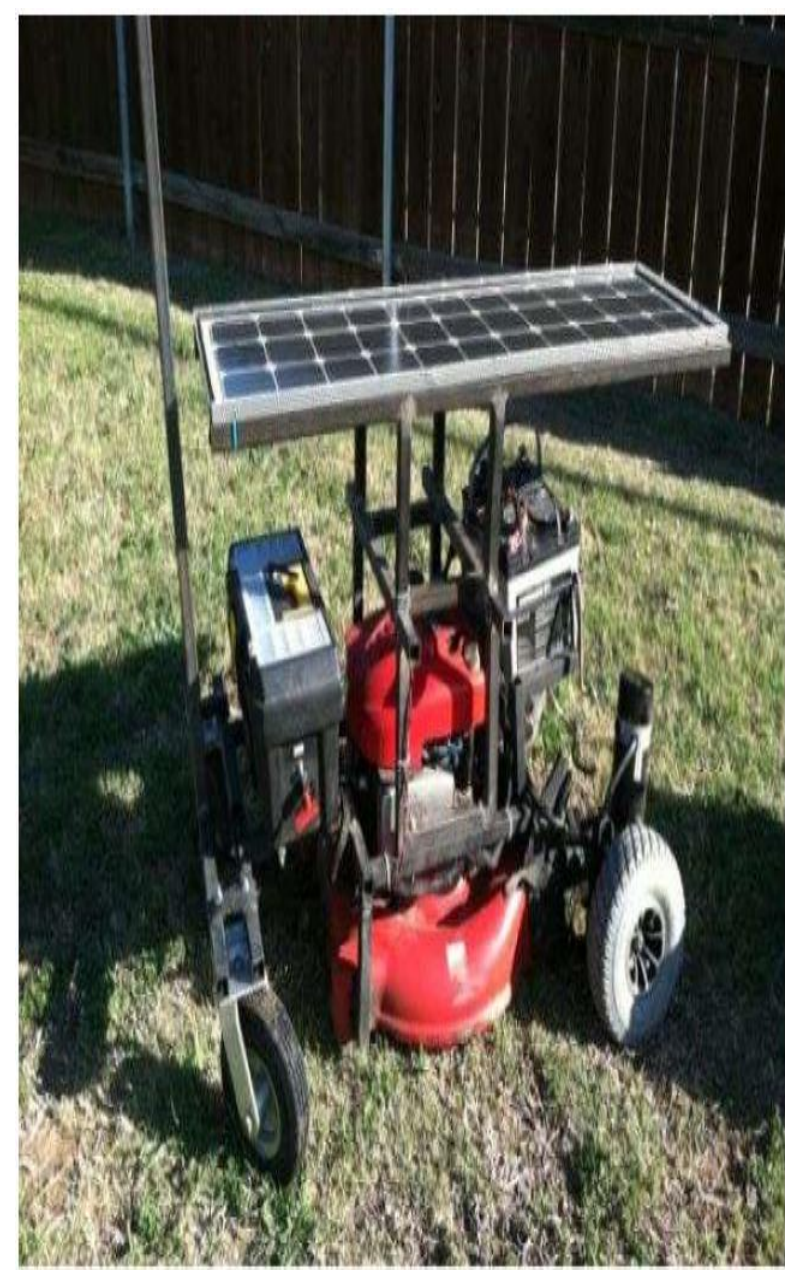

Figure 2. Structure of the proposed work

\section{METHODOLOGY}

The structure contains a microcontroller, sensor, and a solar charging system. Assembling these elements we get our proposed system structure. The sensors are the eyes of the system, we used only colour sensor to obtain the green colour for the cutting of grass and the path where there will no grass the blades will not rotate there. To power the system we used the battery and to charge the battery we used solar panel.

The battery provides the energy required by the components and the motor then move according to the commands. It will also store the grasses which is cut by the grass cutting machine. The effectiveness of our design is that it is emery consuming as the sensor will stop the machine after sensing plane areas (having no grass). And this machine will also remove the hurdles on its way.

The proposed system does not require the human involvement for the operation of the machine. Once the machine is started it will work by itself.

\section{CONCLUSION}

The proposed grass cutter will meet each and every challenges of the environment. This grass cutter is comfortable for residence as well as in commercial places and established that have lawns where tractor driven motor could be used. Further modification of the project is easier for the people as it has very simple and easy structure. The proposed project has many advantages as eco-friendly, no fuel cost, and no residue of the fuels which results pollution free machine. Because of less amount of the moving components the system has less wear and tear. And it can be easily operated by the solar energy. The system has automated charging facility. Therefore, this machine is more suitable for the grass cutting and storing.

\section{REFRENCES}

1. G. Rahul and E. Naresh, "Grass Cutting Machine by Solar Energy Power," Grass Cut. Mach. by Sol. Energy Power, 2016.

2. P. Abhinav Deep, C. Akash Babu, and M. Siva Kumar, "Fully Automatic Solar Grass Cutter Using Arduino," Int. J. Mod. Trends Sci. Technol., 2018.

3. D. N. Kumar, "AUTOMATIC LAWN MOVER USING NI- LABVIEW," Int. J. Adv. Res. Comput. Sci., 2018.

4. S. . S. V. .P, "Smart Lawn Mower for Grass Trimming," Int. J. Sci. Res., 2014.

5. K. B. A. Solomon, S., D. Qin, M. Manning, Z. Chen, M. Marquis and M. T. and H. L. M. (eds.), Climate Change 2007: The Physical Science Basis. Contribution of Working Group I to the Fourth Assessment Report of the Intergovernmental Panel on Climate Change. 2007. 